\title{
MILÁČEK-VITOVEC STAINING METHOD VERSUS CONVENTIONAL AND MOLECULAR ONES FOR DIAGNOSIS OF CYCLOSPORA CAYETANENSIS INFECTION
}

\author{
By \\ EMAN M. HUSSEIN ${ }^{1 *}$ AND AMAL M. ALMATARY ${ }^{2}$
}

Department of Medical Parasitology ${ }^{1,2}$, Faculty of Medicine, Suez Canal University, 41522, Ismailia ${ }^{1}$ and Faculty of Medicine, Assiut University, 71515, Assuit ${ }^{2}$, Egypt.

( ${ }^{*}$ Correspondence: emanmob@hotmail.com)

\section{Abstract}

Stool samples from 150 immunocompromised patients (including 120 Gastrointestinal [GI] symptomatic and $30 \mathrm{GI}$ asymptomatic) suspected to have Cyclospora cayetanensis infection were examined to evaluate the validity of Miláček-Vitovec staining method in comparison with kinyoun stain for the diagnosis of cyclosporiasis. All results were confirmed with nested PCR as a gold standard. Validation parameters included sensitivity, specificity, accuracy index, positive predictive value and negative predictive value. In addition, infection intensity was compared among all positive samples. DNAs of Cyclospora oocysts were detected among 30/120 (25\%) of GI symptomatic patients versus $1.7 \%$ of GI asymptomatic (5/30). Miláček-Vitovec stain showed more validity than kinyoun with a sensitivity reached $80 \%$ versus $73.4 \%$ (28 versus 25 from 35 cases) while the specificities of showed 90.4\% (104/115) versus 81.7\% (94/115), respectively. Mild infection intensity was detected among 10 patients only three of them $(30 \%)$ were detected by Miláček-Vitovec stain while only one (10\%) was detected by Kinyoun, Moderate infection were identified among 10 patients all of them were diagnosed by MiláčekVitovec stain and $9(90 \%)$ was detected by Kinyoun stain. Heavy infection was detected among 15 patients all diagnosed with Miláček-Vitovec stain while 14 were detected with kinyoun.

Key words: Cyclospora cayetanensis, Miláček-Vitovec staining, Conventional \& Molecular ones

\section{Introduction}

Intestinal human coccidian parasites $C y$ clospora cayetanensis have emerged as a significant human gastrointestinal pathogen worldwide that causing prolonged, but selflimited diarrhea in immunocompetent patients, while in immunocompromised, diarrhea may be prolonged, severe and fatal (Ortega and Sanchez, 2010). Cyclosporiasis occurs in persons of all ages (Eberhard et al, 1997). Generally, the infected patients may experience GIT symptoms such as abdominal cramping, diarrhea (about 6stools/day in acute form), anorexia, and nausea, beside other constitutional symptoms such as flulike symptoms, fatigue, weight loss, myalgia, bone ache, joint pain and fever. Routine diagnosis of this parasitic infection may be ignored especially in developing countries (Seyrafian et al, 2011). The presence, frequency, and distribution of Cyclospora parasites in patients with a deficient or suppression of immune system are very important, as it impacts not only the quality of life of these patients but may also have effects on the disease course, therapeutic efficacy and tolerability, and mortality (Seitz and Trammer, 1998). Therefore, improved diagnostic tools for these parasites will feature higher specificity and sensitivity to facilitate more accurate and earlier diagnosis, so that appropriate therapeutic intervention may be initiated in a timely manner (Jiménez-Cardoso et al, 2013). Diagnosis of Cyclospora was done by detection of oocysts in fecal samples using light microscopy by Modified acid-fast (Dixon et al, 2005). Due to the extensive variability on the staining of the oocysts as well as interference with particulate matter within the feces the proficiency in identification of Cyclospora oocysts by light microscopy has been a challenge (Ortega and Sanchez, 2010). Autofluorescent properties of the oocysts as well as interference with particulate matter within the feces beside the intermittent and low level of oocysts shedding complicate epifluorescence microscopic examination (Chacin-Bonilla, 2010) but 
this type of microscopy was not widely available in many laboratories especially in developing countries (Hussein, 2017). Sporulation study is one of the diagnostic tools but it is time consumed and not all of oocysts ablity to sporulate (Ortega and Sanchez, 2010). Also, no immunological or serological diagnosis are available so cyclosporiasis can often be misdiagnosed because of the oocyst detection is the main diagnostic issue (Garcia, 2007). Due to these limitations, molecular-based techniques are more sensitive, specific and time-efficient. Although PCR relies on the genetic information of $C$. cayetanensis yet, did not depend on the subjective nature of the microscopic (Varma et al, 2003). But, this method is expensive, and labor-intensive and the need for specialized equipments and experiences (Ortega and Sanchez, 2010). On the other hand, immunodiagnosis using serological assays to determine human exposure to Cyclospora were yet available (Garica, 2007). The new staining technique overcomes the low sensitivity of conventional staining method is an urgent issue. Aniline-carbol-methyl violet stain of Miláček-Vitovec was successively used in staining and diagnosis of Cryptosporidium oocysts (Miláček and Vitovec, 1985; Holubová et al, 2016).

In this study, the validity of Miláček-Vitovec stain as a new diagnostic stain in the diagnosis of cyclosporiasis was compared to kinyoun stain and confirmed by PCR.

\section{Patients and Methods}

Patients selection :Fecal samples were collected from 120 from the gastrointestinal tract (GIT) symptomatic and 30 were from GIT asymptomatic patients seeking for medical help and attending gastroenterology clinic and different clinics of Suez Canal University Hospitals, Ismailia. Verbal consents were obtained from the patients and all of the procedures were conducted according to the ethical standard approved by the institutional human ethics committee, Faculty of Medicine, Suez Canal University, Egypt.
Fresh stool samples were examined macroscopically. Samples were examined by light microscopy of wet mounts and then by staining (Garcia, 2007). Fresh stool samples were divided into two parts; the first one was concentrated and sediments were stained for microscopical diagnosis and the second part was preserved in $-20^{\circ} \mathrm{C}$ for molecular diagnosis as it is (fresh stool) (Ortega et al, 1993). Each Stool sample was concentrated with mixing of $15 \mathrm{ml}$ saline $(0.9 \%$ sodium chloride) to $5 \mathrm{~g}$ or $5 \mathrm{ml}$ of feces and filtrated through four layers of gauze to remove the coarse material. The filtrate was centrifuged at $800 \mathrm{xg}$ for $5 \mathrm{~min}$. The supernatant was eliminated and the sediment was examined directly by wet mount. A final volume of 1-2 ml was mixed with $10 \mathrm{ml}$ of Sheather's sugar solution that has a specific gravity of 1.27 and centrifuged at $600 \mathrm{~g}$ for 20 min to float many oocysts. The float fluids were collected and examined for the presence of $C$. cayetanensis oocysts after staining by modified Kinyoun (Garica, 2007) and MV (Miláček and Vitovec, 1985). Miláček-Vitovec staining method: The stain includes two solutions (Miláček and Vitovec, 1985), the first one is aniline-carbolmethyl violet that composed of $0.6 \mathrm{gm}$ methyl violet, $1 \mathrm{ml}$ aniline, $1 \mathrm{gm}$ phenol, $30 \mathrm{ml}$ $96 \%$ ethanol and distilled water added to reach $100 \mathrm{ml}$. The solution was lifted for one day and after filtered. The second solution is composed of $1 \%$ tartrazine in $1 \%$ acetic acid. Dry smears were put in methyl alcohol for 5 minutes at room temperature. The smears were stained with aniline-carbol-methyl violet for 30 minutes and after that rinse in tap water. The smear then differentiated in $1-2 \%$ sulphuric acid for 30 seconds tile the slide was pale blue-violet and followed by rinsing with tap water. Finally, the stained smears were put in tartrazine solution to counterstained then rinse briefly with tap water. After the slides became dry the smears were examined.

Intensity of infection: The numbers of oocysts on slides stained by Kinyoun's acid 
fast were counted (Mc-Lauchlin et al, 1999). The means for 20 fields were calculated at x400 magnification. The numbers of oocysts observed were categorized as follows: None: no oocysts, $(+)$ : $<1$ oocyst , $(++)$ : 1-10 oocysts, and (+++): 11- 100 oocysts. If no oocysts were seen in 20 fields, the entire slide was examined thoroughly before the sample was considered negative (Garcia, 2007).

Molecular diagnosis of $C$. cayetanensis: DNA extraction was obtained from $0.5 \mathrm{~g}$ stool specimen homogenized in $8 \mathrm{ml}$ of distilled water and filtered through a $300 \mu \mathrm{m}$ mesh sieve then $3 \mu$ of ether was added, and the water-ether mixture was vortexed for 1 min and centrifuged at $700 \times g$ for $2 \mathrm{~min}$. The pellet was diluted in $100 \mu \mathrm{l}$ of water after decanting the supernatant then DNA was extracted using a QIAmp tissue kit (Qiagen, Hilden, Germany). The extracted DNA was stored at $-20^{\circ} \mathrm{C}$ until further use. Controls DNA stool samples positive and negative for C. cayetanensis oocysts were obtained from our previous study (Hussein et al, 2016).

PCR was performed using $18 \mathrm{~S}$ rRNA as the target in a nested PCR assay using gene oligonucleotide primers F1E (5'-TACCCAAT GAAAACAGTT-3') as the forward primer \& R2B (5'-CAGGAGAAGCCAAGGTAG$\left.3^{\prime}\right)$ as the reverse primer for the external round of PCR to amplify a primary amplicon of 636bp. Then inner primer pair F3E (5'CCTTCCGCGCTTCGCTGCGT-3') \& R4B (5'-CGTCTTCAAACCCCCTACTG-3') as the forward and reverse primers, respectively were used to generate generated a $294 \mathrm{bp}$ amplicon. PCR was conducted at two amplifications rounds (primary and secondary) according to Orlandi et al. (2003). In a total volume of $50 \mu \mathrm{l}$, the primary amplifications round was performed. It contained $20 \mu \mathrm{l}$ of template DNA, $10 \mathrm{mM}$ Tris- $\mathrm{HCl}(\mathrm{pH} 9.0)$, $50 \mathrm{mM} \mathrm{KCl}, 0.1$ Triton X-100, $2 \mathrm{mM}$ $\mathrm{MgCl} 2,200 \mu \mathrm{M}$ of each dNTP, dCTP dGTP and dTTP, $0.2 \mu \mathrm{M}$ of each primers F1E and R2B and 1.25 units of Taq DNA. An initial activation of the HotStarTaq DNA polymerase at $95^{\circ} \mathrm{C}$ for $15 \mathrm{~min}$ was begun. Then, the denaturation cycle was performed at $94 \mathrm{oC}$ for 30 seconds for 35 cycles followed by annealing at $53 \mathrm{oC}$ for 30 seconds and primer extensions at $72^{\circ} \mathrm{C}$ for 90 seconds. Then a final extension cycle followed at $72 \mathrm{oC}$ for 10 min in an ABI 2720 thermocycler (ABI Biosystems, USA). After that, the second round was conducted in a reaction volume of $50 \mu \mathrm{l}$ and $5 \mu \mathrm{l}$ of the primary round product was used as a template. Reaction component concentrations were the same as in the primary round with the following exceptions: the primers used were $\mathrm{F} 3 \mathrm{E}$ and $\mathrm{R} 4 \mathrm{~B}$ and the annealing temperature was increased to $60 \mathrm{oC}$. The nested PCR products were examined after electrophoresis on a $1.5 \%$ agarose gel, stained with $0.2 \mu \mathrm{g} / \mathrm{ml}$ of ethidium bromide and visualized on a UV transilluminator.

Statistical analysis: Validation parameters included sensitivity, specificity, accuracy index (positive predictive value and negative predictive value. Significance difference was measured by chi-square test or Fisher exact test. P-value $\leq 0.05$ was statistically significant.

\section{Results}

In the present study, 35 Cyclosporapositive fecal samples were confirmed with nested PCR by the production of Cyclospo$r a$-amplicons out of 150 detected by either of Miláček-Vitovec or kinyoun stain. Variably kinyoun stain oocysts measure $8-10 \mu \mathrm{m}$ in diameter (Fig.1a,b,c) as the sporulated and unsporulated oocyst have variability on staining reaches to completely unstained oocyst. By Miláček-Vitovec stain all the sporulated and unsporulated were stained. On the other hand, sporulated oocysts were presented darker than unsporulated (Fig 2 a,b). DNAs of Cyclospora oocysts were detected among 30/120 (25\%) of GI symptomatic patients versus $1.7 \%$ of GI asymptomatic (5/30) (Fig. 3a \&b). Miláček-Vitovec stained only 28 out 35 of true positive so its sensitivity was $80 \%$ while its specificity was $90.4 \%(104 / 115)$ with an accuracy index reached $88 \%$. Positive and negative predic- 
tive value was $89.8 \%$ \& $93.7 \%$, respectively. Regarding kinyoun, sensitivity was $73.4 \%$ (25/35) specificity was $81.7 \%$ (94/115) and accuracy index was $79.1 \%$. Positive and negative predictive values were $76.4 \%$ and $90.1 \%$, respectively (Tabs. $1 \& 2$ ). As regarding to the intensity of infection, 10 samples had mild infection three of them were detected by MV stain while only one was detected by Kinyoiun, Moderate infection

Table 1: Comparison between of MV and Kinyoun stains versus nested PCR as gold standard diagnosis.

\begin{tabular}{|l|l|c|c|c|c|c|c|}
\hline \multicolumn{2}{|c|}{} & \multicolumn{2}{c|}{ Nested PCR (Gold standard) } \\
\hline \multirow{2}{*}{} & \multicolumn{2}{c|}{ Positive } & \multicolumn{2}{c|}{ Negative } & \multicolumn{2}{c|}{ Total } \\
\cline { 3 - 8 } \multicolumn{2}{|c|}{} & No & $\%$ & No & $\%$ & No & $\%$ \\
\hline \multirow{3}{*}{ MV } & Positive & 28 & 80 & 11 & 9.6 & 39 & 26 \\
\cline { 2 - 8 } & Negative & 7 & 20 & 104 & 90.4 & 111 & 74 \\
\cline { 2 - 8 } & Total & 35 & 100 & 115 & 100 & 150 & 100 \\
\hline \multirow{3}{*}{ Kinyoun } & Positive & 25 & 73.4 & 21 & 18.3 & 45 & 30 \\
\cline { 2 - 8 } & Negative & 10 & 28.6 & 94 & 81.7 & 105 & 70 \\
\cline { 2 - 8 } & Total & 35 & 100 & 115 & 001 & 150 & 100 \\
\hline
\end{tabular}

Table 2: Evaluations of validation parameters for of MV \& Kinyoun stains vs. nested PCR a gold standard.

\begin{tabular}{|l|c|c|c|c|c|}
\hline & Sensitivity & Specificity & Accuracy index & Positive Predictive value & Negative Predictive value \\
\hline MV & 80 & 90.4 & 88 & 89.7 & 93.7 \\
\hline Kinyoun & 73.4 & 81.7 & 79.4 & 76.1 & 90.4 \\
\hline
\end{tabular}

Table 3 Intensities of infection with each stain

\begin{tabular}{|l|l|c|c|c|c|c|c|}
\hline \multicolumn{2}{|c|}{} & \multicolumn{2}{|c|}{ Mild positive } & \multicolumn{2}{c|}{ Moderate positive } & \multicolumn{2}{c|}{ Heavy positive } \\
\cline { 3 - 8 } \multicolumn{2}{|c|}{} & No & $\%$ & No & $\%$ & No & $\%$ \\
\hline \multirow{4}{*}{ MV } & Positive & 3 & 30 & 10 & 100 & 15 & 100 \\
\cline { 2 - 8 } & Negative & 7 & 70 & 0 & 0 & 0 & 0 \\
\cline { 2 - 8 } & Total & 10 & 100 & 10 & 100 & 15 & 100 \\
\hline \multirow{3}{*}{ Kinyoun } & Positive & 1 & 10 & 9 & 90 & 14 & 93.4 \\
\cline { 2 - 8 } & Negative & 9 & 90 & $1 *$ & 10 & $1 *$ & 6.6 \\
\cline { 2 - 8 } & Total & 10 & 100 & 10 & 100 & 15 & 100 \\
\hline
\end{tabular}

*oocyst failed to stain completely, with significant difference

\section{Discussion}

Until now, no animal models, tissue culture or monoclonal antibodies are available to study human Cyclospora infection (Eberhard et al, 2000; Karanis et al, 2007). Although the acid-fast staining method is considered the easiest and most practical and provides a stained slide it can lead to misdiagnosis due to the variability in staining and confusion with artifacts (Eberhard et al, 1997). Lainson (2005) recommended the molecular-based technique as reliable method for $C$. cayetanensis identification.

This study showed that Miláček-Vitovec stain is more valid than kinyoun with no variability on the stain. Chu et al. (2004) and Khalifa et al. (2004) emphasized that the nested PCR had $100 \%$ sensitivity and speci- ficity, therefore, it is the confirmatory diagnostic method, in the present study, for the detecting cyclosporiasis infection. Furthermore, the possibility of cross-detection between the presence of Cyclospora and Eimeria species by nested PCR is not possible, because no Eimeria infection was present yet in human (Pieniazek et al, 1996; Relman et al, 1996). Although, nested PCR is still the most popular and confirmatory method used to detect Cyclospora DNA (Betancourt et al, 2002; Steele et al, 2003; JiménezCardoso et al, 2013; Orozco-Mosqueda et al. 2014; Hussein, 2017). Yadav et al. (2015) proved that PCR assay amplified $C$. cayetanensis DNA in only 89\% (17/19) isolates. This variability on the sensitivity of PCR was explained by Orlandi et al. (2002) who 
stated that the molecular diagnostic methods generally still depend on the ability to isolate and concentrate the parasites from samples matrix as well as ability to prepare a suitable DNA template free of matrix-derived substances that may interfere with PCR results. Also, lacking PCR in many laboratories, particularly in developing countries led to limitations as use in routine diagnosis.

In the present study, 35 Cyclospora-positive fecal samples were confirmed with nested PCR out of 150 stained by Miláček-Vitovec and/or kinyoun. The sensitivity of kinyoun stain was very low (73.4\% (2535/) and specificity was low $(81.7 \%)$. Sensitivity and sp-ecificity of Miláček-Vitovec stain in $C y$ clospora oocysts were $80 \%$ \& $90.4 \%$ respectively. There were false results by using the staining techniques compared to PCR. However, the false negative and false positive results were shown by using Kinyoun technique, statistically- higher than that shown by Miláček-Vitovec staining. These data agreed with Betancourt et al. (2002), Steele et al. (2003) and Khalifa et al. (2004) who found that the sensitivity and specificity of staining methods were lower if compared to molecular techniques. Moreover, the modified kinyoun stain showed great variability in the staining pattern of Cyclospora oocysts leading to decrease in its sensitivity (Visvesvara et al, 1997; Negm, 1998). Also, it was neither timely nor specific (Orlandi et $a l, 2003)$. All these problems led to limitation of the kinyoun staining diagnostic method (Garcia, 2007). In the present study, Miláček-Vitovec stain was used for the first time in diagnosis Cyclospora infection. This present data agreed with Kváč et al. (2003) who compared different methods for routine diagnostics of Cryptosporidium spp to Miláček-Vitovec stain and found that specificity of both stainings was $95-100 \%$, respectively. Ziehl-Neelsen was more suitable for identification of $C$. andersoni and modified MV for $C$. parvum identification.

As regarding to the intensity of infection, 10 samples had mild infection three $(30 \%)$ of them detected by Miláček-Vitovec stain while only one $(10 \%)$ was detected by Kinyoun, Moderate infection was identified among 10 patients all of them were diagnosed by Miláček-Vitovec stain while 9 was detected by Kinyoun stain and one was completely missed because it failed to stain. Heavy infection was detected among 15 patients all of them were diagnosed with Miláček-Vitovec stain while 14 were detected with kinyoun and rest one was completely missed because it failed to stain. The differences were statistically significant.

In case of infection intensity, the microscopic counts of Cyclospora oocysts are still the gold standard (Ortega et al, 1998; Varma et al, 2003). Also, detection limits of nested PCR was 10 oocysts per inoculated fecal sample (Sturbaum et al, 1998), no samples were found to be positive by staining and negative with PCR as repeated PCR for all samples positive with staining twice. Sometime, no samples were positive by both stains and negative with PCR.

The infection rate of C. cayetanensis was in a hospital in Honduras (2002-2011) with $1.3 \%$ (125/9984), based on Ziehl-Nielsen Carbol fuchsin staining (Kaminsky et al, 2016). But, a lower infection rate $(0.67 \%$, 60/8877) was detected in a pediatric hospital (patients aged $<15$ years) in Mexico (in 2000-2009), based on morphometric characteristics and PCR (Orozco-Mosqueda et al, 2014). A higher prevalence $(3.94 \%, 20 / 507)$ was detected in school children (aged 314years) in Nepal, with modified acid-fast staining (Bhandari et al, 2015), and a markedly higher rate was reported in humans in Italy $(27.5 \%, 11 / 40)$, based on quantitative PCR (Giangaspero et al, 2015). On the study of Vijay Prakash Singh et al. (2015) the prevalence of Cyclospora parasites among 62 immunocompromised patients with diarrhea was found to be $4.8 \%$ and in immunocompromised patients without diarrhea, no infection was seen. The prevalence of cyclosporiasis was carried out by Ziehl Neelsen staining and PCR among immunosuppressed pa- 
tients, including 96 individuals with the human immunodeficiency virus or 77 having acute lymphoblastic leukemia with or without diarrhea. It was $7.3 \%$ among diarrheic patients, whereas, the prevalence was zero for Cyclospora spp. among non-diarrheic (Jiménez-Cardoso et al, 2013).

\section{Conclusion}

A Miláček-Vitovec staining for $C$. cayetanensis oocysts proved to be sensitive, specific, accurate and efficient. Thus, can be applied for laboratory diagnosis even in mild and moderate infection in spite of being time consuming than Kinyoun. Molecular methods are clearly more promising than microscopy, however, staining examination is not dispensable as lacking PCR in many laboratories that lead to limitations of its user.

\section{References}

Bhandari, D, Tandukar, S, Parajuli, H, Thapa, P, Chaudhary, P, et al, 2015: Cyclospora infection among school children in Kathmandu, Nepal: Prevalence and associated risk factors. Trop. Med. Hlth. 43:211-6.

Betancourt, W, Peele, E, Rose, J, 2002: Cryptosporidium parvum and Cyclospora cayetanensis; a review of laboratory methods for detection of these water born parasites. J. Microbiol. Meth. 49, 3: 209-24.

Chu, T, Sherchand, B, Cross, H, Orlandi, A, 2004: Detection of Cyclospora cayetanensis in animal fecal isolates from Nepal using an FTA filter-base PCR method. Am. J. Trop. Med. Hyg. 71, 4:373-9.

Chacin-Bonilla, L, 2010: Epidemiology of $C y$ clospora cayetanensis, a review focusing in endemic areas. Acta Trop.115:181-93.

Dixon, BR, Bussey, JM, Parrington, LJ, Parenteau, M, 2005: Detection of Cyclospora cayetanensis oocystsin human fecal specimens by flow cytometry. J. Clin. Microbiol. 43:2375-9.

Eberhard, L, Ortega, R, Hanes, E, Nace, E, Do, F, et al, 2000: Attempts to establish experimental Cyclospora cayetanensis infection in laboratory animals. J. Parasitol. 86, 3:577-82.

Eberhard, ML, Pieniazek, NJ, Arrowood, M J, 1997: Laboratory diagnosis of Cyclospora infections. Arch. Pathol. Lab. Med. 121:792-7.

Garcia, LS, 2007: Diagnostic Medical Parasitology $5^{\text {th }}$ ed. Washington DC: ASM Press.

Giangaspero, A, Marangi, M, Koehler, AV,
Papini, R, Normanno, G, et al, 2015: Molecular detection of Cyclospora in water, soil, vegetables, and humans in southern Italy signals a need for improved monitoring by health authorities. Int. J. Food Microbiol. 211:95-100.

Holubová, N, Sak, B, Horčičková, M, Hlásková L, Květoňová, D, et al, 2016: Cryptosporidium parvum n. sp. (Apicomplexa: Cryptosporidiidae) in birds. Parasitol. Res. 115, 6:2243-51.

Hussein, E, 2017: Chapter 3 Cyclospora Cayetanensis: Still an enigmatic pathogen.

Hussein E, El-Moamly, A, Mahmoud M, Ateek N, 2016: Wide genetic variations at $18 \mathrm{~S}$ ribosomal RNA locus of Cyclospora cayetanensis isolated from Egyptian patients using high resolution melting curve. Parasitol. Res. 115, 7:797806.

Hussein, E, El-Moamly, A, Dawoud, H, Fahmy, H, El-Shal, H, Sabek, N, 2007: Realtime PCR and Flow cytometry in the detection of Cyclospora oocysts in fecal samples of gastrointestinal symptomatic and asymptomatic pediatric patients. J. Egypt. Soc. Parasitol. 37, 1:151-70

Jiménez-Cardoso1, E, Eligio-García, L, Cano, A, Cortés, A, Medina, A, et al, 2013: Frequency of emerging parasites in HIV/AIDS and oncological patients stool by coprological and molecular analysis. Adv. Infect. Dis. 3:162-71

Kaminsky, RG, Lagos, J, Raudales Santos, G, Urrutia, S, 2016: Marked seasonality of Cyclospora cayetanensis infections: ten-year observation of hospital cases, Honduras. BMC Infect. Dis. 16:66-9.

Karanis, P, Kourenti, C, Smith, H, 2007: Waterborne transmission of protozoan parasites: A worldwide review of outbreaks and lessons learned. J. Water Hlth. 5, 1:1-38.

Khalifa, E, El-Nouby, K, Ismail, H, Amin, A, 2004: Environmental study for the potential sources of Cyclospora and pathogenicity of the isolated oocysts in experimental model. Egypt. J. Med. Microbiol. 13, 2:461-73.

Kváč, D, Květoňová, G, Pưžová, O, 2003: Comparison of selected diagnostic methods for identification of Cryptosporidium parvum and Cryptosporidium andersoni in routine examination of faeces. J. Vet. Med. 8:363-416.

Lainson, P, 2005: Genus Cyclospora (Apicomplexia: Eimeriida) with a description of Cyclospora Scheider n. sp. in the snake Anilius scytale (Aniliidae) from Amazonian Brazil, a review. Mem. Inst. Oswaldo. Cruz. 100, 2:103-10. 
Miláček, P, Vitovec, J, 1985: Differential staining of Cryptosporidia by aniline-carbol methyl violet and tartrazine in smears from feces and scrapings of the intestinal mucosa. Folia Parasitol. 32:50-4.

Negm, A, 1998: Identification of Cyclospora cayetanensis in stool using different stains. J. Egypt. Soc. Parasitol. 28, 2:429-36.

Orlandi, A, Chu, D, Bier, J, Jackson, G, 2002: Parasites and the food supply. Food Technol. 56, 4:72-81.

Ortega, YR, Sterling, CR, Gilman RH, Cama, VA, Díaz FN, 1993: Cyclospora species, a new protozoan pathogen of humans. Engl. J. Med. 328, 18:1308-12.

Ortega, Y, Sterling, C, Gilman, R, 1998: $\mathrm{Cycl}$ ospora cayetanensis. Adv. Parasitol. 40:399418.

Ortega, YR, Sanchez, R, 2010: Update on Cyclospora cayetanensis, a Food-Borne and Waterborne Parasite. Clin. Microbiol. Rev. 23:218-34. Orlandi, PA, Carter, L, Brinker, AM, Da Silva, AJ, Chu, DM, et al, 2003: Targeting singlenucleotide polymorphismsin the 18S rRNA gene to differentiate Cyclospora species from Eimeria species by multiplex PCR. Appl. Environ. Microbiol. 69:4806-13.

Orozco-Mosqueda, GE, Martínez-Loya, OA, Ortega, YR, 2014: Cyclospora cayetanensis in a pediatric hospital in Morelia, México. Am. J. Trop. Med. Hyg. 91:537-40.

Pieniazek, N, Slemenda, S, da Silva, A, Alfano, E, Arrowood, M, 1996: PCR confirmation of infection with Cyclospora cayetanensis. Emerg. Infect. Dis. 2:357-9.

Relman, A, Schmidt, M, Gajadhar, A, Sogin, M, Cross, J, et al, 1996: Molecular phylogenetic analysis of Cyclospora, the human intestinal pathogen, suggests that it is closely related to Eimeria species. J. Infect. Dis., 173:440-5.

Seyrafian, SN, Pestechian, N, Namdari, M, Aviani, M, Kerdegari, 2011: Prevalence of parasitic infections in Iranian stable hemodialysis patients. Appl. Med. Inform. 29: 31-6.

Steele, M, Ungar, S, Odumeru, J, 2003: Sensitivity of PCR detection of Cyclospora cayetanensis in raspberries, basil, and mesclun lettuce. J. Microbiol. Meth. 54, 2:277-80.

Seitz HM, Trammer T, 1998: Opportunistic infections caused by protozoan parasites. Tokai J. Exp. Clin. Med. 23:249-57

Sturbaum, D, Ortega, Y, Gilman, R, Sterling, R, Cabrera, L, et al, 1998: Detection of Cyclospora cayetanensis in wastewater. App. Environ. Microbiol. 64, 6:2284-6.

Varma, M, Hester, D, Schaefer, W, Ware, W, Lindqist, A, 2003: Detection of Cyclospora cayetanensis using a quantitative real-time PCR assay. J. Microbiol. Meth. 53:27-36.

Vijay, PS, Chimanjita, P, Hazarika, NK, 2015: Prevalence of intestinal coccidian parasite in immunocompromised patients in a tertiary care center in Assam Int. J. Pharm. Biol. Sci. 5, 4:67-73.

Visvesvara, G, Moura, H, Kovacs, Nace, E, Wallace, S, Eberhard, L. 1997: Uniform staining of Cyclospora oocysts in fecal smears by a modified safranin technique with microwave heating. J. Clin. Microbiol. 35:730-3.

Yadav, P, Khalil, S, Mirdha, BR, Makharia, GK, Bhatnagar, S, 2015: Molecular characterization of clinical isolates of Cyclospora cayetanensis from patients with diarrhea in India. Indian J. Med. Microbiol. 33, 3:351-6

\section{Explanation of figurres}

Fig.1: Cyclospora oocyst under light microscopy X1000: Fig 1a Completely stained unsporulated oocyst by Kinyoun stain green; Fig 1b: Partialy stained sporulated oocyst by Kinyoun stain Fig1c:Oocyst unstained by Kinyoun and stained with malachite green.

Fig. 2 Cyclospora oocyst under light microscopy X1000; fig.2a Unsporilated Cyclospora oocyst stained with Miláček-Vitovec. Fig 2b. sporulated Cyclospora oocyst stained with Miláček-Vitovec

Fig. 3 a\&b-: Examples of DNA assays of fecal samples by Nested PCR. $M=$ a ladder DNA at 100 bp. a; Positive and negative controls in lane $1 \& 2$ respectively. Cyclospora positive samples were present in lanes $4,5 \& 7$ found at 294 bp while lanes 2,3 \&6 were negative. f ig $3 b$; lanes $10,11,12,14,15$ positives, lanes $13 \& 16$ negatives. 

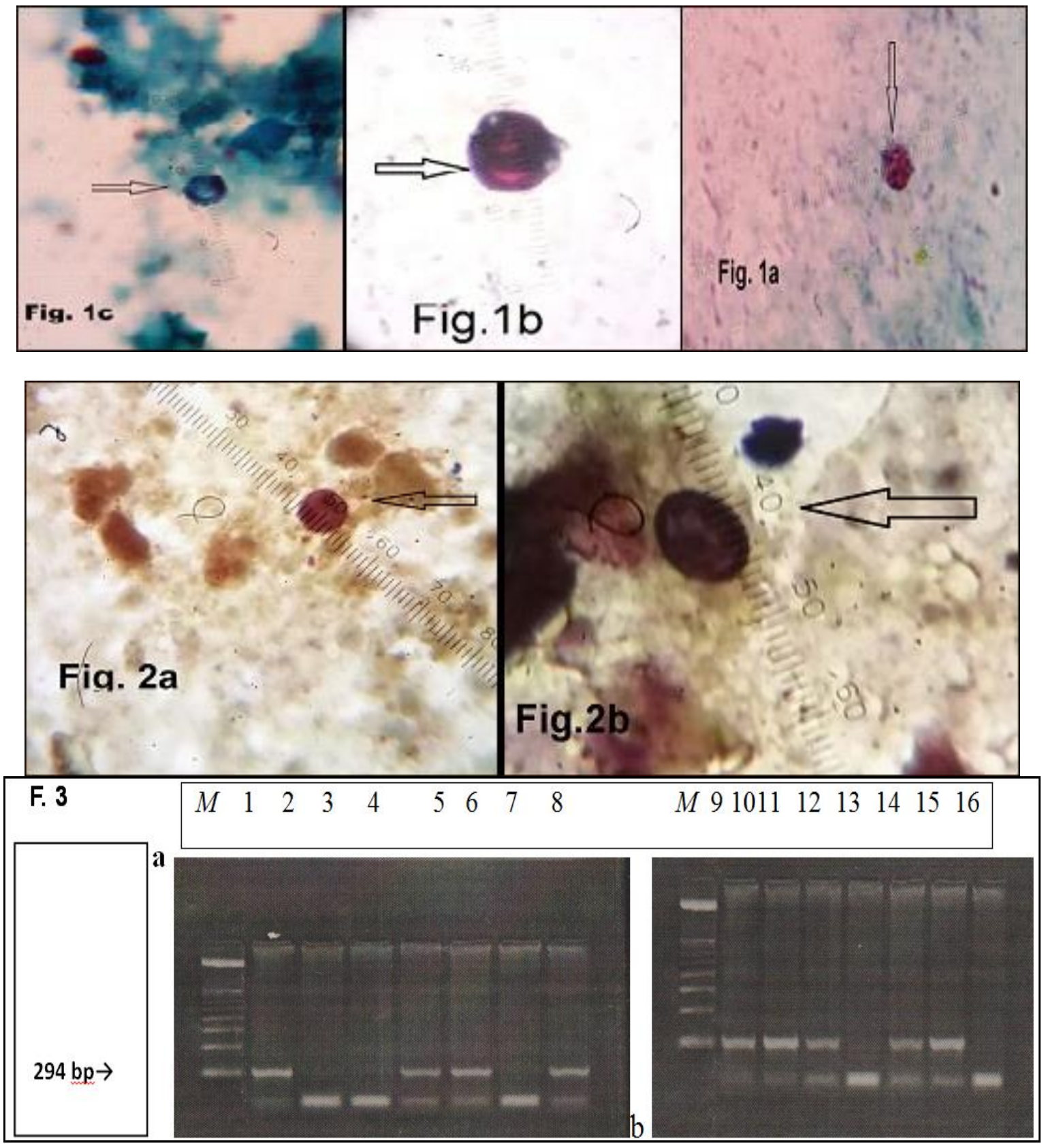